\title{
Parque de Mar Puerto Barón
}

BORIS IVELIC

$>$ Escuela de Arquitectura, Pontificia Universidad Católica de Valparaíso. boris.ivelic@ead.cl

\section{PABLO VÁSQUEZ}

> Magister Arquitectura y Diseño, mención Náutico y Marítimo, Pontificia Universidad Católica de Valparaíso. pablo.vasquez@gmail.com

Universidad de Valparaíso

Facultad de Arquitectura

Revista Márgenes

Espacio Arte Sociedad

Parque de Mar Puerto Barón

Septiembre 2014 Vol 11 NN$^{\circ} 14$

Páginas 94 a 107

ISSN elec. 0719-4463

ISSN imp. 0718-4034

Recepción: mayo 2014

Aceptación: agosto 2014

\section{RESUMEN}

Los principales puertos del mundo, han sufrido un cambio radical a partir de la invención del container. Se ha racionalizado el uso del suelo y se han demolido los “muros" que lo separaban de la ciudad. El puerto de Valparaíso gestiona con una empresa de retail un mall en puerto Barón. El Municipio lo aprueba y una parte importante de la ciudadanía lo rechaza.

El anteproyecto alternativo que aquí se presenta, pretende contribuir al debate sobre una obra ubicada en un lugar emblemático de la ciudad, en que está en juego el destino marítimo de Valparaíso. El borde costero prácticamente está vedado como espacio público y el porcentaje de área verde es de los más bajos de Chile. Valparaíso está en crisis.

El anteproyecto propone un parque marítimo, con una doble instancia: modelar la tierra del parque como área verde de recreación y deportes y permitir la entrada controlada del mar para generar espacios habitables de navegación y baño. Parque con accesos desde la ciudad y desde el mar, con edificios-vínculos, entre el cerro Barón y el parque y edificios flotantes que no alteren las rasantes visuales. Éstos permitirán la sustentabilidad y viabilidad económica del proyecto. Consolidar en Barón un parque isla protegido, para que su gente se pueda beneficiar de este extraordinario bien que le regala el Océano Pacífico a Valparaíso.

PALABRAS CLAVE

parque, marítimo, Valparaíso, destino, gestión, conflicto

\section{Puerto Barón sea park}

ABSTRACT

Main ports in the world have faced a radical change since the container was invented. The use of the land has been rationalized and the "walls" that separated them from the city have been demolished. Local authorities are negotiating with a retail company the building of a shopping mall. While the local government supports the project, a great part of the population is against it.

The alternative project proposed here aims to take part on the debate about a construction located in an emblematic place in the city. The future of Valparaíso as a promenade is at risk. The coastline is no longer a public space and the percentage of green areas is one of the lowest in Chile. Valparaiso is in crisis.

The alternative project proposes a promenade, with a double objective: to shape the land as a green area for sports and recreation and allow a controlled entrance of the sea to create inhabitable spaces for navigation and swimming. The sea park will be accessible from the city as well as from the sea, with buildings that will connect Cerro Barón and the parks and floating buildings that will not interfere with the view. These buildings will make the viability of the project possible. The objective is to consolidate a protected island park in Barón so that the community can benefit from this extraordinary gift given by the Pacific Ocean to the city of Valparaíso. KEYWORDS

sea park, Valparaíso, destiny, management, conflict

\section{Parc de Mer Puerto Barón}

\section{RÉSUMÉ}

Les principaux ports du monde ont souffert un changement radical à partir de l'invention du container. On a rationalisé l'utilisation du sol et on a démoli les "parois" qui le séparaient de la ville. Le port de Valparaiso gère avec une entreprise retail d'un mall à port Barón. La Municipalité l'approuve et une partie importante de la citoyenneté le rejette. 
L'avant-projet alternatif qui est ici présenté prétend contribuer au débat sur une œuvre située dans un lieu emblématique de la ville, où la destination maritime de Valparaíso est en jeu. Le bord côtier est pratiquement fermé en tant qu'espace public et le pourcentage d'espace vert est un des plus faibles des villes du Chili. Valparaiso est en crise.

L'avant-projet propose un parc maritime, avec une double instance : modeler la terre du parc comme un espace vert de récréation et sports et ainsi permettre l'entrée contrôlée de la mer pour produire des espaces habitables navigation et de bain. Un parc avec des accès depuis la ville et depuis la mer, avec des liens, entre la colline Baron et le parc et les bâtiments flottants qui n'altèrent pas les rasantes visuelles. Ceux-ci permettront la durabilité et la viabilité économique du projet. Consolider un parc île protégé à Barón, pour que ses gens puissent profiter de ce bien extraordinaire donner par l'Océan Pacifique à Valparaíso.

\section{MOTS CLÉS}

parc, maritime, Valparaíso, destin, gestion, conflit

\section{ORIGEN EL PROYECTO}

Los puertos del mundo han sufrido un cambio radical, a partir de la invención del container. Esto ha racionalizado el uso del suelo portuario, reduciendo drásticamente su superficie y permitiendo "derribar el muro" que separaba el puerto de la ciudad. Estos espacios ganados, se han convertido en espacios públicos de primera importancia de las ciudades portuarias del mundo. El puerto de Valparaíso no ha sido ajeno a esta realidad y hoy debate su destino en relación a su ser ciudad.

En este sentido, la ciudad de Valparaíso tiene negada la relación con su borde y el puerto. Este hecho ha impulsado la elaboración de proyectos y planes maestros en el sector donde se emplaza el Muelle Barón, con el objetivo de vincular la ciudad con el mar para la recreación y el goce de todos sus habitantes. Ante esta situación, se procura elaborar un proyecto que involucra a las siguientes entidades: Empresa Portuaria de Valparaíso; el Estado, a través de la Municipalidad de Valparaíso, MOP, Ministerio de Vivienda; Merval; Puerto Valparaíso Deportivo.

\section{ACTUALIDAD DEL PROYECTO}

De las propuestas que se han presentado, se ha escogido, y se discute, la construcción de un Mall (centro comercial) en el Muelle Barón, propuesta del grupo "Plaza Valparaíso S. A." Esta situación que ha provocado malestar en distintos sectores y organizaciones de la ciudad, tanto por el impacto comercial y vehicular que se generaría en la zona, como por su propuesta arquitectónica. Ellos manifiestan: Un Mall es un edificio construido para mirar hacia adentro, no para reconocer y elogiar el borde costero donde se emplaza. Esto es una contradicción con la apertura de este lugar como espacio público.

En torno a este debate la opinión ciudadana está dividida, entre los que se oponen a la construcción de un mall en estos terrenos y los que lo promueven. Sin embargo, en los proyectos alternativos todos consideran el mall.

Este anteproyecto pretende aportar con una doble opción: tratar el lugar no sólo desde la tierra, sino también desde el mar y que per- mita dilucidar qué es lo más conveniente para la ciudad, abriendo el debate a nuevas opciones.

\section{IMPORTANCIA DE RESOLVER EL PROYECTO}

Puerto Barón debe ser hoy uno de los terrenos más importante y significativo de la ciudad de Valparaíso: a. por su ubicación; b. por la magnitud de área despejada; c. por poseer aproximadamente 800 mts. de borde costero; d. por la convergencia de sus vías de circulación.

La ciudad de Valparaíso tiene un 0,3\% de área verde por habitante, lo normal es un 13\%, (en Valdivia es un 19\%) y prácticamente negado su acceso al borde costero. La ciudad no ha constituido algo fundamental para sus habitantes como es la re-creación, el deporte gratuito cotidiano, los espacios culturales.

Por esto queremos exponer este anteproyecto, como una proposición abierta, que pueda ser debatida a todos los niveles y que pueda ser mejorada, completada o rechazada.

\section{Objetivo General}

Creación del espacio de borde costero público: Parque de Mar Puerto Barón.

Extender el suelo habitable de la ciudad a través de un borde permeable, proyectando una entrada de mar y entradas de la ciudad hacia el mar, a través de elementos arquitectónicos fijos y móviles, en que el movimiento de las mareas, las corrientes, el oleaje y los posibles tsunamis, son requerimientos esenciales que debe abordar el anteproyecto.

\section{Objetivos Específicos}

1. Desde el mar: Constituir en Barón un mar interior protegido, un mar habilitado a múltiples opciones, para que sus ciudadanos se beneficien de este extraordinario bien que regala el Océano Pacífico a Valparaíso, dando cabida a: una marina pública; un puerto de embarcaciones menores y de turismo; una caleta; un extenso

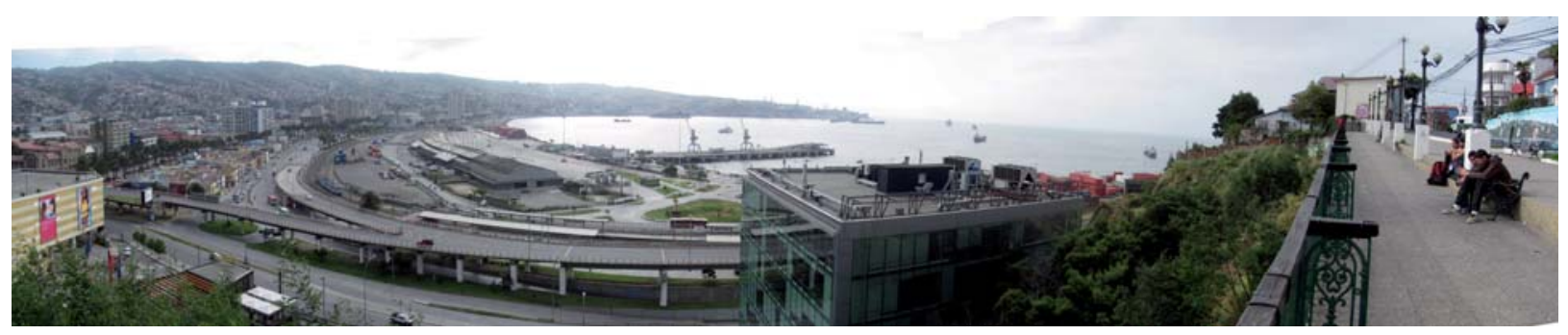

> Figura 1. Muelle Barón. Fotografía autores 2014 
balneario con playa; la práctica de deportes náuticos: kayak, remo, canoa, windsurf y pesca deportiva.

2. Desde tierra: Extender el trazado urbano del barrio Almendral, conectándolo fluidamente al Parque de Mar Puerto Barón, evitando obstáculos y muros transversales, rediseñándose las circulaciones viales y dando cabida a las áreas verdes del parque con: picnic, paseos, ciclovías, trote y canchas de deportes: fútbol, básquetbol, vóleibol, tenis.

3. Se mantiene la Bodega Simón Bolívar (declarado inmueble de conservación histórica), por el valor arquitectónico de su estructura tri-articulada. Evitar que sea un obstáculo visual y físico, permitiendo albergar un programa abierto: museos, exposiciones, conciertos, acuarios, librerías, restaurantes, hotel para eventos, comercio en las alas laterales del segundo piso.

Los objetos patrimoniales que se rescaten de las excavaciones arqueológicas podrían constituir el museo histórico de Valparaíso, en uno de sus módulos.

4. Diseñar unos edificios que formen parte espacial del parque, con un uso mixto: a. para el arriendo o venta a privados: locales, departamento, oficinas, hotel. b. espacio público propio del parque: plazas techadas, accesos, funiculares.

Edificios que permitan contribuir a la viabilidad del proyecto y su mantención, sin impedir las visuales y ocupando menos de un $20 \%$ de la superficie del parque.

\section{FUNDAMENTOS}

\section{Sobre el destino marítimo}

Nuestra Escuela de Arquitectura y Diseño desde su refundación en 1952, ha planteado en sus fundamentos que Valparaíso y Chile, no han asumido la realidad del Océano Pacífico, (carencia) como un elemento determinante en su destino. Destino entendido como una voluntad que es dirigida a una determinación, a un fin, a una misión. A continuación realizamos un estracto de los principales proyectos, tesis y teorías, a lo largo de estos años sobre el Pacífico, que nos dan bases para este anteproyecto que presentamos.

- En 1954 se publica el Estudio Urbanístico para una Población Obrera en Achupallas.

Por primera vez se plantea que el destino de Valparaíso está en el mar. El proyecto y su tesis crea una estructura urbana de conexión directa de Achupallas con el borde marítimo.

El urbanista descubre el destino de la ciudad y la coloca en el espacio, para que la ciudad y sus habitantes vivan su destino (Cruz, 1954:8).

¿Pero tiene Valparaíso un destino? (p. 9).

Valparaíso ha olvidado el mar: quizás la dureza del mar lo ha hecho vacilar.

La orilla del mar está vedada: la gente marinera que ve llegar los buques desde los cerros no puede llegar hasta el borde del agua; la gente de tierra no puede tomarse en ninguna terraza ningún refresco; nadie puede nunca mojarse los pies en el agua (p. 16).

Se ha perdido la orilla, se ha perdido el misterio de la unión del agua con la tierra, del agua con la roca, con el molo, del agua y arena y cuando hemos perdido el borde dado nuestra más profunda metafísica espacial de hoy, hemos perdido la forma, hemos perdido el mar en Valparaíso (p. 16).

- En 1967 se publica el poema Amereida y se produce la proclamación de la épica americana en que el "Océano Pacífico" y el "Mar Interior de América" (extensión deshabitada y sin fundación del interior de América del sur) son los dos grandes desconocidos que nuestro continente no ha asumido como posible destino americano.

- En 1969 presentamos el Proyecto de la avenida del mar. Proyecto alternativo a la Vía Elevada, (MOP) como elemento generador de una nueva estructura urbana del borde costero para Viña del Mar y Valparaíso:

\section{[...] Primer elemento urbano de la ciudad}

Valparaíso, ciudad que se coloca frente al Océano Pacífico para testimoniar el destino Marítimo de nuestra Patria cuidando no abandonando la orilla del mar (AAVV, 1969:41).

- En 1970 se publica la Tesis del Pacífico, en donde se fundamentan las "carencias" históricas y actuales de Chile y América de no haber asumido la realidad del Océano Pacífico.

Hoy 13 naciones somos ajenas al pacífico; los andes son muralla y el océano un mar norteamericano (y ruso). Sólo con el mar interior tendremos océano. Únicamente quienes asumen su continentalidad se proyectan -hoy- al Océano Pacífico. Ni Asia, ni Australia, ni América Latina, por esto llamamos al océano: carencia (que falta y nos llama) (AAVV, 1970:32).

- En 1971 se publica Maritorio de los archipiélagos de la Patagonia Occidental.

Maritorio (concepto análogo a territorio). La palabra nace en Valparaíso a propósito de un estudio sobre la razón de ser de la localización de sus ciudades costeras.

Tal como se funda en el territorio, surge el maritorio como concepción de magnitud de mar.

El Maritorio es un concepto de área geográfica que conjuga: la comunicabilidad, la riqueza, el arraigo y la energía.

Para poblar hay que fundar en la complejidad del área - "maritorio"- única manera de constituir ciudad. Fundar con un solo fin no es poblar (puede ser defender, explotar, etc.). Solo nos conduce a establecer factorías o campamentos (Sánchez, 1971:1).

- En 1972 realizamos y exponemos públicamente el Proyecto del Estero de Viña del Mar, publicado además en la revista CA.

La obra propuesta deja entrar al interior de la ciudad el agua de mar. Se quiere transformar el estero en un brazo de mar. La obra propone que este Elemento Urbano se convierta en la columna vertebral transformadora y renovadora de la ciudad, llevando la vida del mar al interior mismo de ella, con su fauna y sus embarcaciones pesqueras deportivas y turísticas (AAVV, 1972:42).

- En 1982 se publica el libro Aysén Carta del mar nuevo, visión de Aysén como tierra de la "trapananda", que según su etimología es trampa, engaño y cárcel y que aún no resuelve esta nominación, a pesar de haber entrado al siglo XXI. 
- En 1984 publicamos El Pacífico es un mar erótico.

[...] el mar interior no se va a revelar nunca. Esto lo dice Amereida después de su propia travesía: mientras no se revele el Océano Pacífico. El mar interior no se va a revelar nunca. Esto creo yo ha sido olvidado...

[...] el uno por el otro, el Pacífico por el "mar interior" y el "mar interior" por el Pacífico. América va a adquirir mundialidad solo por el Pacífico. Tiene el Atlántico y no tiene mundialidad. Sigue siendo una factoría (Iommi, 1984:1).

- En 1985 publicamos un artículo en la revista CA, "Nuestra Latitud Patagonia" es una visión de la Patagonia Occidental a partir de la teoría de maritorio y su posibilidad fundacional.

el archipiélago (maritorio) fue señalado como tierra inhóspita y la teoría Butland la dividió en habitable e inhabitable. Darwin la tildó de desierto verde e inútil (p. 16).

Al sobreponer América Austral con el norte de Europa, a iguales latitudes, podemos verificar ciudades plenas como Ámsterdam, Berlín, Glasgow, Dublín y otras igualmente plenas están en latitudes más extremas: Helsinki, Estocolmo, Oslo (Baixas, Ivelic, 1985:150)

- En 2006 publicamos Chile es un Archipiélago.

"Archi" significa muchos, innumerables, talvez infinitos. "Piélago" significa océano y mar, pero también abismos e inmensidades. Un archipiélago no es un conjunto de islas, sino un conjunto de mares. $Y$ esa diferencia es radical. Chile es un archipiélago porque se encuentra rodeado por un conjunto de mares: El Océano Pacífico, El mar presencial, El mar interior de América, El mar nuevo de Aysen, El Atlántico (Reyes, 2006).

- En 2006 creamos el postgrado en "Arquitectura y Diseño, mención Náutico y Marítimo". Como reclamo de nuestra propia interioridad y para ser consecuentes con nuestros postulados, fundamos este postgrado. El cuerpo de profesores lo constituye un equipo de ingenieros: marítimo, civiles hidráulicos, de fluidos, naval, arquitecto naval, un oceanógrafo y la planta de arquitectos y diseñadores del magíster. Además cuenta con los equipos de laboratorios para los distintos ensayos de modelos hidráulicos. Este soporte nos permite plantear el presente anteproyecto.

Exponemos algunos extractos de tesis que nos ligan al presente anteproyecto.

- 2008. Tesis de grado N\&M: “Concepción del agua como elemento arquitectónico de revitalización. Proyecto Jardín del agua en el estero Margamarga de Viña del Mar".

Actualización del proyecto de 1972, mediante dragados del estero se introduce el agua de mar y un segundo tramo de dársenas escaIonadas y esclusas, que controlen los flujos y permitan resguardo ante crecidas.

Mediante rompeolas sumergidos de resguardo (invisibles), observar desde el interior del estero el horizonte marino, que trae la dimensión de vastedad oceánica y conciencia de "brazo de mar" (Saona, 2008:93).

- 2009. Tesis de grado N\&M: “Puerto en aguas interiores protegida. Puerto parque humedal en la desembocadura del río Aconcagua".
La desprotección del Puerto de Valparaíso y el impacto urbano en su posible expansión, requieren plantear un nuevo terminal marítimo complementario. La desembocadura del río Aconcagua, es el lugar apropiado por ubicación, enclave y protección natural (Soza, 2009:5).

- 2010. Tesis de grado N\&M: "Destino Marítimo y ciudad. Recuperación del borde costero entre Viña del Mar y Valparaíso".

Se trata de tres tesis correspondiente a cada tramo: Caleta AbarcaCurva los Mayos / Curva los Mayos-Yolanda / Yolanda-Barón. Actualiza el proyecto Avenida del Mar de 1969. Este proyecto introduce el agua calma al borde costero en forma de dársenas, piscinas, canales. Agua que es contenida a través de modelar la tierra.

La avenida España es un tubo continuo que ocupa el ancho total del borde, impide detenerse al automóvil y le niega al peatón acceder a la playa. La vía elevada (MOP) redujo Caleta Abarca, eliminó la playa Poca Ola y arrasó con el balneario Recreo y su piscina (Baeza, 2010:4).

- 2011. Tesis de grado N\&M: "El mar como territorio habitable en Valparaíso (Barón y Yolanda). Museo del mar Pacífico Sur".

Mediante un modelo marítimo de prueba realizado en el sector Barón y Yolanda, se demostró la hipótesis de que el muelle Barón es un puerto desprotegido, al sufrir frontalmente los embates de las olas.

\section{El agua como elemento urbano}

En el origen de las ciudades siempre estuvo presente el agua: para abastecerse de ella en el consumo doméstico y ser un elemento de circulación. Luego eran ciudades puertos, lacustres o fluviales.

En Egipto el faraón Ramsés, fundó una gran ciudad en uno de los deltas del Nilo. En el transcurso del tiempo el delta cambió su curso dejando sin río la ciudad. Ramsés mandó trasladar la ciudad al nuevo curso, lo que implicaba cambiar de lugar los gigantescos muros de piedra con que estaba construida.

Con la invención de la cañería, el abastecimiento de agua doméstico no dependió necesariamente del río y con la invención de otros medios de circulación por tierra o por aire dejó de ser el único medio para la circulación. Hoy principalmente en Europa y en las grandes ciudades, es un espacio de paseo, de contemplación y un elemento de seguridad para evitar crecidas e inundaciones. Las aguas que surcan la ciudad, se han transformado en un "elemento urbano".

Recorrer contemplativamente las ciudades europeas en un automóvil, es casi imposible. Entre el requerimiento de la velocidad y la fluidez, es difícil detenerse a contemplar algo que nos llama la atención, no se puede pasear en automóvil. Los obstáculos propios de ella, cruces semáforos, peatones, no permiten circular lentamente. En cambio abordar embarcaciones de paseo, por los mares, ríos o lagos, permiten una navegación sin obstáculos, tranquila, se reconoce la ciudad y se la puede contemplar relajadamente, sin las tensiones del tráfico de tierra.

Las aguas generan bordes, crean espacios amplios, lejanías, distancias, vacíos, costaneras, hitos ciudadanos, referencias.

Valparaíso lamentablemente abovedó la avenida Argentina. 


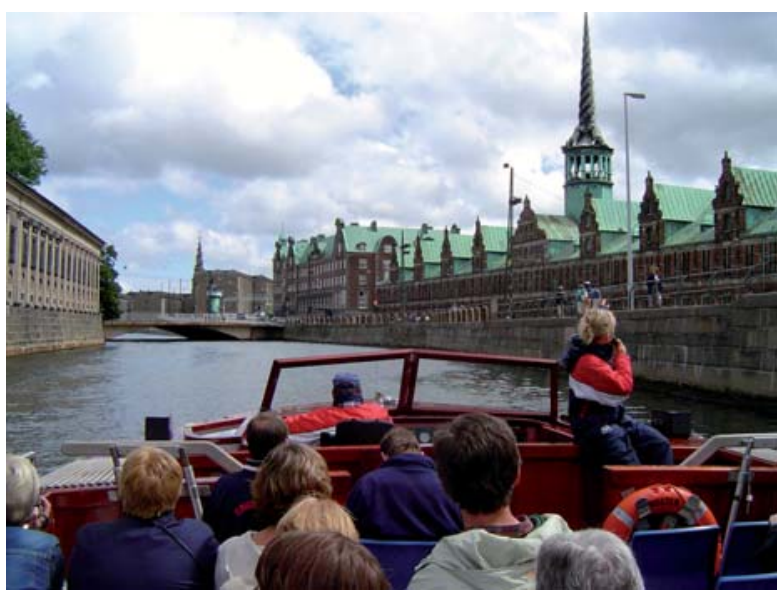

$>$ Figura 2. Copenhagen, se contempla la ciudad paseando por los canales urbanos. Fotografía autor, 2007

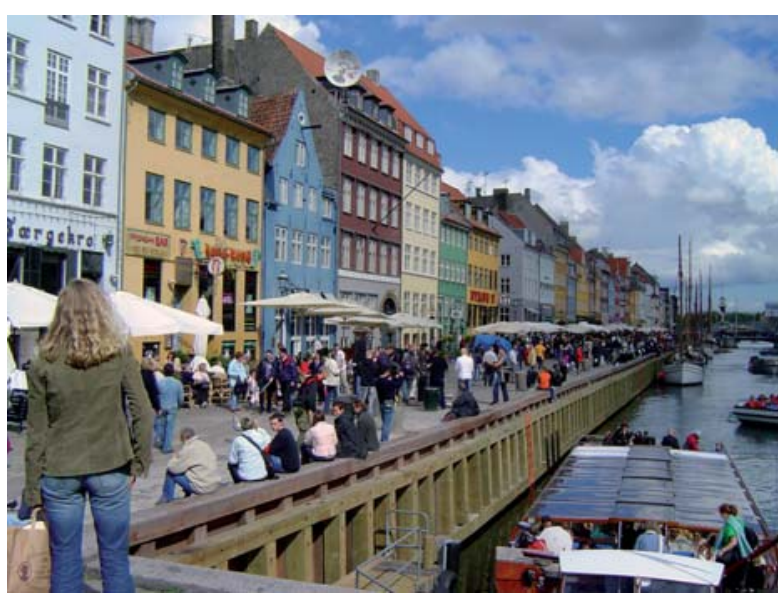

> Figura 3. Copenhagen, paseo fluvial y peatonal. Fotografía autor, 2007
El urbanismo de las grandes ciudades, incorpora el agua como elemento constitutivo urbano: piénsese en Venecia, París y el río Sena, Hamburgo y sus aguas fluviales y lacustres. En las ciudades nórdicas de Copenhagen, Estocolmo, Oslo y Helsinki , el agua y la tierra se entrelazan, Holanda es atravesado por una red de canales navegables. Lo mismo la ciudad del Tigre en Argentina que hace del delta del Paraná una ciudadela con canales de circulación.

En Chile también son elementos potenciadores de la ciudad: nuestra ciudad puerto de Valparaíso, que lucha por recuperar su orilla, las ciudades balnearios de Viña del Mar, La Serena, que ha acercado la ciudad al mar; la ciudad fluvial de Valdivia; las ciudades lacustres de Puerto Varas, Pucón y Villarrica. Son ciudades elegidas para el descanso y el turismo.

Tierra y agua, lo fijo y lo móvil, continente y contenido. Se dice el agua toma la forma del elemento que lo contiene, del sólido. El agua es un fluido, fluye. Construimos la forma del agua a través de dar forma a la tierra: dársena, canal, marina, puerto, balneario, caleta, playa. Pueden ser aguas quietas, aguas con corriente, aguas turbulentas, rápidos, saltos. Se las puede controlar: en un canal, subir o bajar su nivel con compuertas; proteger el borde costero mediante rompeolas o muros, también provistos de compuertas; cerrar entradas de mar mediante barreras de protección.

Conclusión: es a través de la tierra, del sólido, que se construye la forma del agua.

No se puede competir con el mar abierto como es nuestro Pacífico.

En el tempestuoso mar del norte, los importantes Puertos de Rotterdam, Amberes y Hamburgo, están ubicados en las cuencas de Ios ríos Mosa, Escalda y Elba, respectivamente. Puertos completamente protegidos de olas y temporales, con reservas suficientes para sitios de atraque y futuras ampliaciones.

La tendencia mundial de los puertos, a partir de las Olimpíadas de Barcelona, es “derribar sus muros”, e integrarlos al espacio ciudadano. Así se transforman, acogiendo paseos, marinas, miradores, restaurantes.

Sólo hay ciudad cuando coexisten el ocio y el negocio, sino es un campamento o factoría (Amereida II).

En Europa y en muchas lugares del mundo, el borde costero es el espacio público de todos sus ciudadanos. Es de todos y no es de nadie. No se puede construir en ese borde, no es un espacio inmobiliario. Algunos dicen es el espacio patrimonio de todos los hombres. Nos pone en contacto con todos los continentes.

Lamentablemente el borde marítimo de Valparaíso, se asemeja más a un sector industrial de postguerra. Hemos desvalorizado nuestro mar. Lo hemos contaminado, ya prácticamente no tenemos pesca, es peligroso bañarse en nuestras pocas playas.

\section{Sobre gestión urbana}

En la década del 50, frente a la congestión vehicular, Boston construye una de las primeras vías elevadas en el mundo. Con el devenir del tiempo se satura y aparece el deterioro al que ha sido expuesta la ciudad, cortándola en dos, contaminando su aire y su acústica.

En la década del 90, el secretario de transporte Frank Salbucci propone un cambio revolucionario, proclama: hay que demoler los errores urbanos, reemplazándolos por autopistas subterráneas y parques. En un prodigio ingenieril, se construyen los túneles sin detener el tráfico. Así la ciudad es reoriginada. El muro que signifi- 
caba la vía elevada y que separaba la ciudad del mar, es demolido y transformado en un parque.

Los ciudadanos de Boston recobran el mar, el paseo a pie, nuevas áreas verdes y vuelven a disfrutar de su hermosa ciudad.

En São Paulo una de las ciudades más congestionadas del mundo, la infrestructura de tránsito: avenidas, autopistas, metro, ferrocarril, sólo logran paliar un tercio de las necesidades, con ello se producen tacos de hasta cinco horas. Hoy las autoridades, los urbanistas y los arquitectos critican la falta de previsión que debió tomarse hace treinta años.

Como se explicó en el capítulo sobre el destino marítimo, la Escuela de Arquitectura y Diseño de la PUCV desarrolló un proyecto de la Avenida del Mar en el año 1969, para la unión de Valparaíso y Viña del Mar. Proyecto que era contrapartida al de la Vía Elevada del Ministerio de Obras Públicas, que proponía una nueva vía expresa elevada en pilotes sobre el borde marítimo (que hoy es la Avenida España).

Por primera vez se desencadenó en Chile una acción pública, en defensa de Valparaíso y Viña del Mar, ante una obra que a juicio de la Escuela atentaba contra la propia ciudad. El slogan que presidía la exposición era: La tierra de Chile es el mar.

Fue una acción que movilizó a toda la Escuela, con exposiciones públicas en Valparaíso y también en Santiago, generándose una polémica pública a través de exposiciones, en la radio, televisión, y diarios.

Hoy la ciudadanía está consciente de sus derechos, como se ha demostrado con la oposición al mall Barón.

El libro Valparaíso Reclamado de Pablo Andueza y Pablo Aravena contiene la "Minuta Ejecutiva" que un conjunto de organizaciones ciudadanas presentó a los inspectors de UNESCO el pasado 27 de Noviembre, a propósito del Mall Barón:

[...] Resulta inquietante ver cómo la gestión patrimonial de la ciudad -entregada a privados sin la regulación requerida- a ratos parece derechamente ir en "contra" de Valparaíso (p. 10).

Más adelante agregan: Cuando las empresas portuarias del país no están en condiciones de rentar los recintos portuarios con el negocio marítimo-portuario, la alternativa más fácil es la que hoy se quiere hacer en la ciudad: entregarla al retail. Vía de financiamiento fácil (p. 32).

[...] De concretarse el proyecto comercial en Barón, se haría imparable el uso inmobiliario intensivo en el área norte de la bahía, desde calle Edwards hasta Yolanda. Las fuerzas ciudadanas, desmoralizadas por la instalación del retail, no podrían frenar el "tsunami" constructivo, que es absolutamente previsible (p. 33).

[...] No se sabe, entonces, cuál es el aporte urbano de un proyecto así de individualista y autárquico (Andueza, Aravena, 2013).

Otro modo de desvalorizar el borde costero, es taparlo con un mall. Es negar su destino, es transformar el mar en una espalda.

Los malls en otros países están en las afueras de la ciudad. Tratan de evitar que se altere la escala urbana y se congestione el tráfico, como ha ocurrido con Puerto Montt, Castro, Puerto Varas. En Viña se han deteriorado las tradicionales calles del paseo y del comer-

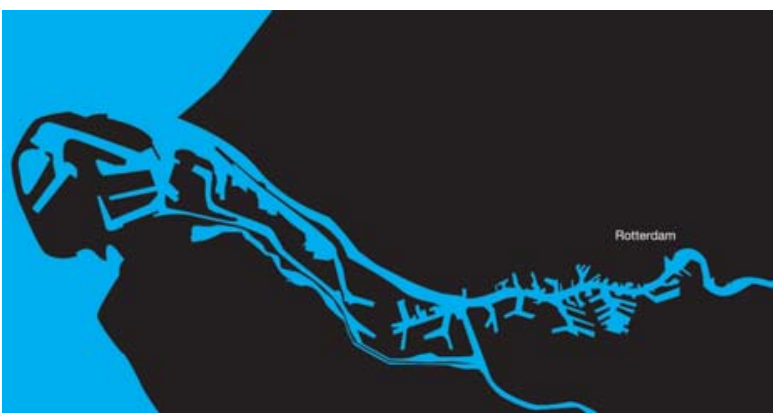

Figura 4. El Puerto de Rotterdam, ubicado en el interior protegido del río Mosa. Es una extensión de 8 kilómetros, con 40 kilómetros de borde portuario construido. Fuente: Elaboración propia, 2014

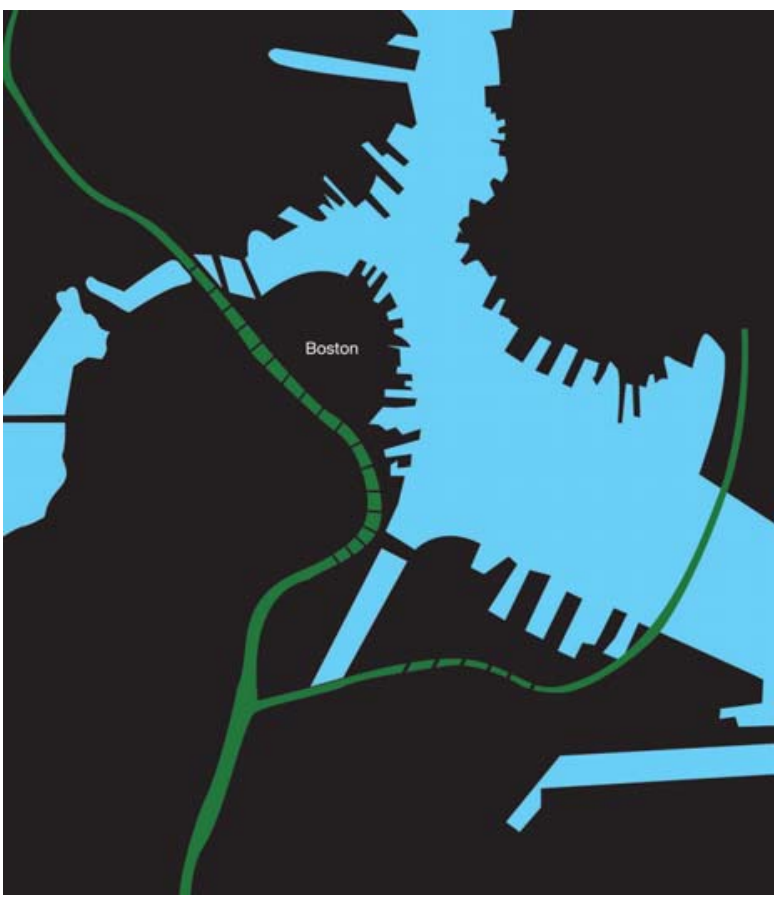

Figura 5. Plano de la autopista subterránea de la ciudad de Boston. Anteriorrmente ocupada por una vía elevada, hoy demolida y convertida en parque y acceso al mar. Fuente: Elaboración propia, 2014 


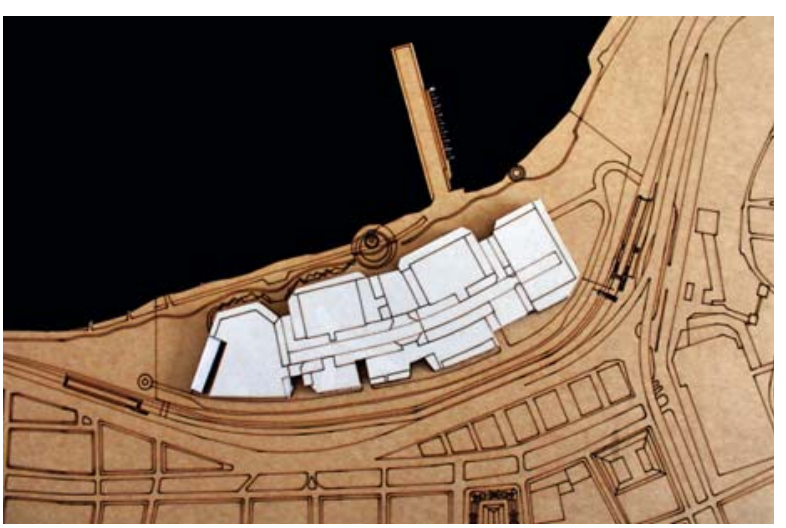

$>$ Figura 6. Fotografía de la maqueta del mall Barón propuesto por la empresa "Plaza Valparaíso Sociedad Anónima". Se puede apreciar la ocupación invasiva del lugar, desvalorizando el borde costero y generando una espalda al mar. Fuente: Elaboración propia, 2013

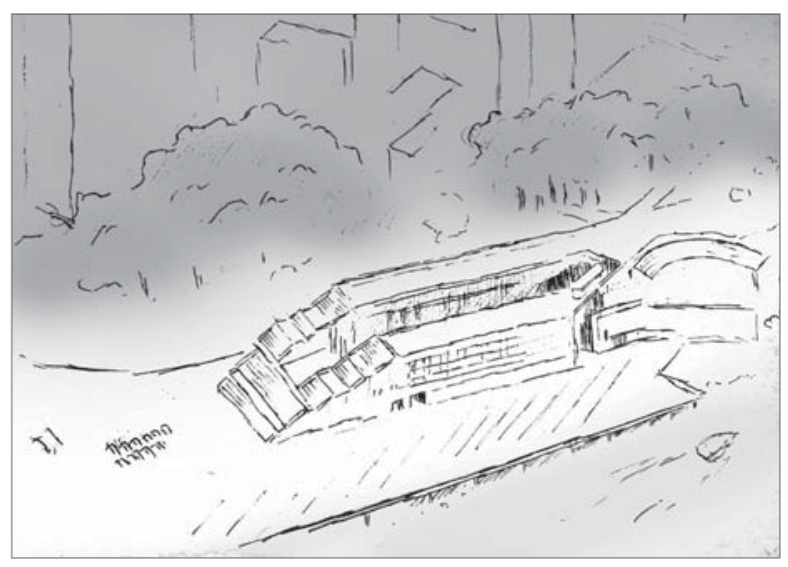

Figura 7. Croquis del Centro Cultural Plaza España, del arquitecto Catalán Oriel Bohigas, Rosario, Argentina. La coexistencia del espacio público y privado. Fuente: Elaboración propia, 2014 cio. Un mall puede estar en cualquier parte, un puerto o un parque de mar, no, dice la ciudadanía.

La obra que se pretende nace, si es que nace, sin el consentimiento mayoritario de sus ciudadanos. Si se construye no será una obra de la que puedan enorgullecerse. Una obra en que la ciudad se abra al mar, que le dé sentido a esta ciudad, que es su patrimonio y del cual no está agradecido. Espacio que dé cabida a la recreación, a la cultura, por sobre el apetito inmobiliario y el negocio pasajero e inmediatista.

No estamos en contra que particulares y empresas puedan participar en este proyecto, ya que es la única manera de financiarlo, pero se debe concebir como un gran espacio público. A partir de lo público se pueden constituir los espacios privados. No corresponde que un mall lo absorva todo y sea administrado como un espacio privado.

No se puede entregar a los particulares ni menos a una empresa de retail el espacio público urbano. Corresponde al estado velar por el espacio que es de todos. En Chile debiera existir una reforma urbana. Una entidad que esté por sobre los intereses particulares, los intendentes y los alcaldes y que estudia, planifica y controla la ciudad, tal como lo fue la CORMU (Corporación de Mejoramiento Urbano) en la década del 60. Políticas de continuidad a largo plazo, no de discontinuidad como son los períodos presidenciales. Chile requiere una visión y proyecto de país en permanencia en el tiempo. Son demasiadas las autoridades y organismos que están comprometidas con el muelle Barón y es y ha sido muy difícil ponerlas de acuerdo.

La ciudadanía opina que la tragedia del incendio de Valparaíso se debe a su abandono. Abandono desde su origen. Las poblaciones de las cumbres de nuestra ciudad, apenas alcanzan a ser un campamento. La ciudad reacciona movida por la compasión. Pensamos es la oportunidad para refundarlo todo, pero comprobamos que no se está preparado para estas catástrofes. Empieza la reconstrucción sobre lo mismo, en las mismas condiciones. Mediaguas de emergencia. Lo provisorio, que se torna definitivo.

No es concebible que Valparaíso no tenga mar ni parques. En las grandes ciudades se "descansa" en la propia ciudad. Sus ciudadanos se enorgullecen del lugar en que viven, son "guías" de su ciudad para los parientes y amigos que los visitan.

Este lugar debe ser el "Central Park" de Valparaíso. Cuánto valdrá un terreno en el Central Park de Nueva York. Ese es el orgullo de un neoyorkino, no se han dejado seducir por el apetito inmobiliario de esos terrenos. ¿Los porteños se dejarán seducir? Hasta ahora han dado la pelea.

Víctor Gubbins (premio nacional de arquitectura) nos señala: Reafirmar un destino y precisar un nuevo rol, requiere de intervenciones mayores y de decisión y coraje, tal como la tuvieron nuestros ancestros que fueron capaces de rellenar el Almendral para aumentar el plan de Valparaíso, hacer el camino de Cintura, los ascensores, y el mismo puerto. Grandes obras, producto de la iniciativa de grandes hombres (Gubbins:3).

\section{Los estándares urbanos actuales}

La Avenida del Mar de 1969, planteaba que éste era el primer elemento urbano de la ciudad, elemento complejo por tanto y no solamente una autopista. Hace 40 años, Chile vivía otra realidad económica y vehicular, hoy las autopistas concesionadas urbanas son más eficientes y rentables. En esa época era impensable hundir el ferrocarril como hoy lo ha hecho Viña del Mar o concebir la costanera norte en Santiago y el metro. 


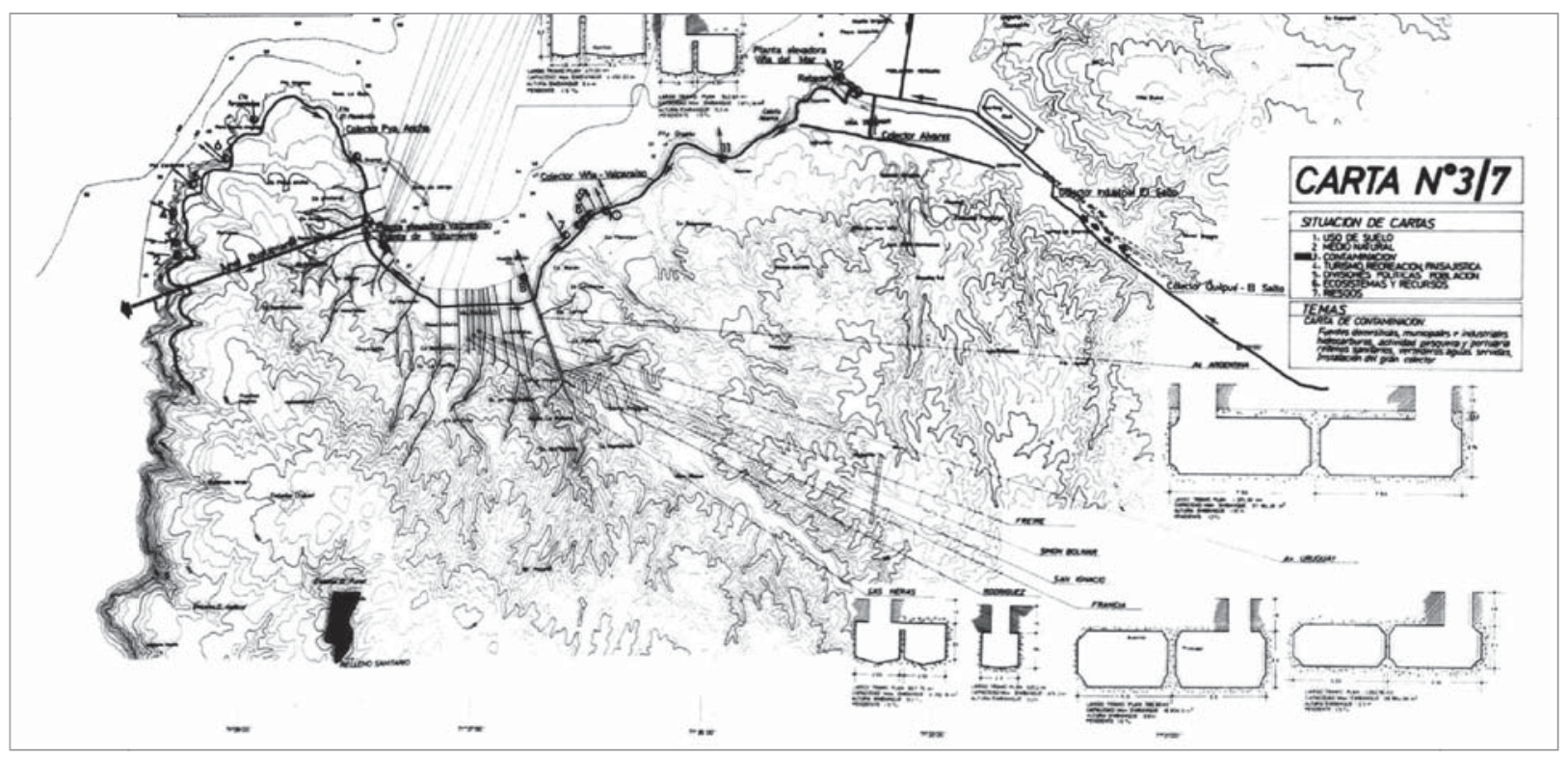

Figura 8. Fragmento de ubicación y cortes de los cauces de Valparaíso, que desembocan en el parque propuesto. Fuente: Carta de contaminación bahía de Valparaíso. Esteban Morales, Consuelo Castro, Luis Álvarez, 1987

\section{Del patrimonio histórico}

El subsuelo de muelle Barón, es un sitio declarado patrimonio arqueológico. Luego la extracción de la tierra para construir las obras marítimas, debe ser motivo de estudios y supervigilancia arqueológica y la ejecución realizada por expertos, con todos los cuidados que amerita una intervención de esta naturaleza. Los objetos patrimoniales que se rescaten, podrían formar un museo, en una parte del edificio.

Pronunciamiento del Seremi de Vivienda y Urbanismo, Matías Avsolomovich:

[...] Cuando estos inmuebles se declaran, se recoge una serie de atributos y valores que justifican las razones que determinaron la definición del inmueble como de conservación histórica.

[...] arquitectura y patrimonio, con el "proyecto estructural" y con el "sistema de evacuación ante tsunami".

[... de acuerdo a lo que establece la ficha del PRC, está relacionada con el largo y tamaño del inmueble de 300 metros, y con la estructura de marcos de hormigón armado.

[...] Desde el punto de vista arquitectónico, ambos factores están recogidos en el proyecto de refacción, ya que el valor del edificio es principalmente su área interior. En la propuesta se plantea que los marcos de hormigón armado sea a la vista, destacando esta característica del edificio.

[..]. El sistema de reforzamiento no es a través de elementos sobrepuestos, sino mediante técnicas modernas no invasivas a la estructura del edificio. (Avsolomovich, 2013, El Martutino, 20.01.13).

\section{De lo público y lo privado}

En la ciudad de Rosario, Argentina, en el borde del río Paraná, existe un complejo llamado Centro Cultural Plaza España del arquitecto catalán Oriel Bohigas. Edificio conector de la costanera con la plaza (ubicada a una cota más alta). Se accede al edificio desde la costanera, mediante un frontis de escaleras (anfiteatro) que conduce a dos

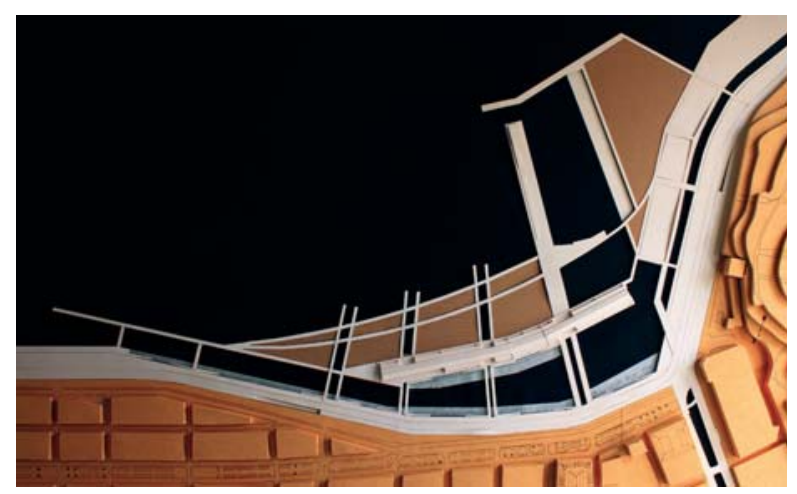

$>$ Figura 9. Fotografía de la maqueta preliminar del Parque de Mar Puerto Barón. Fuente: Elaboración propia, 2013 


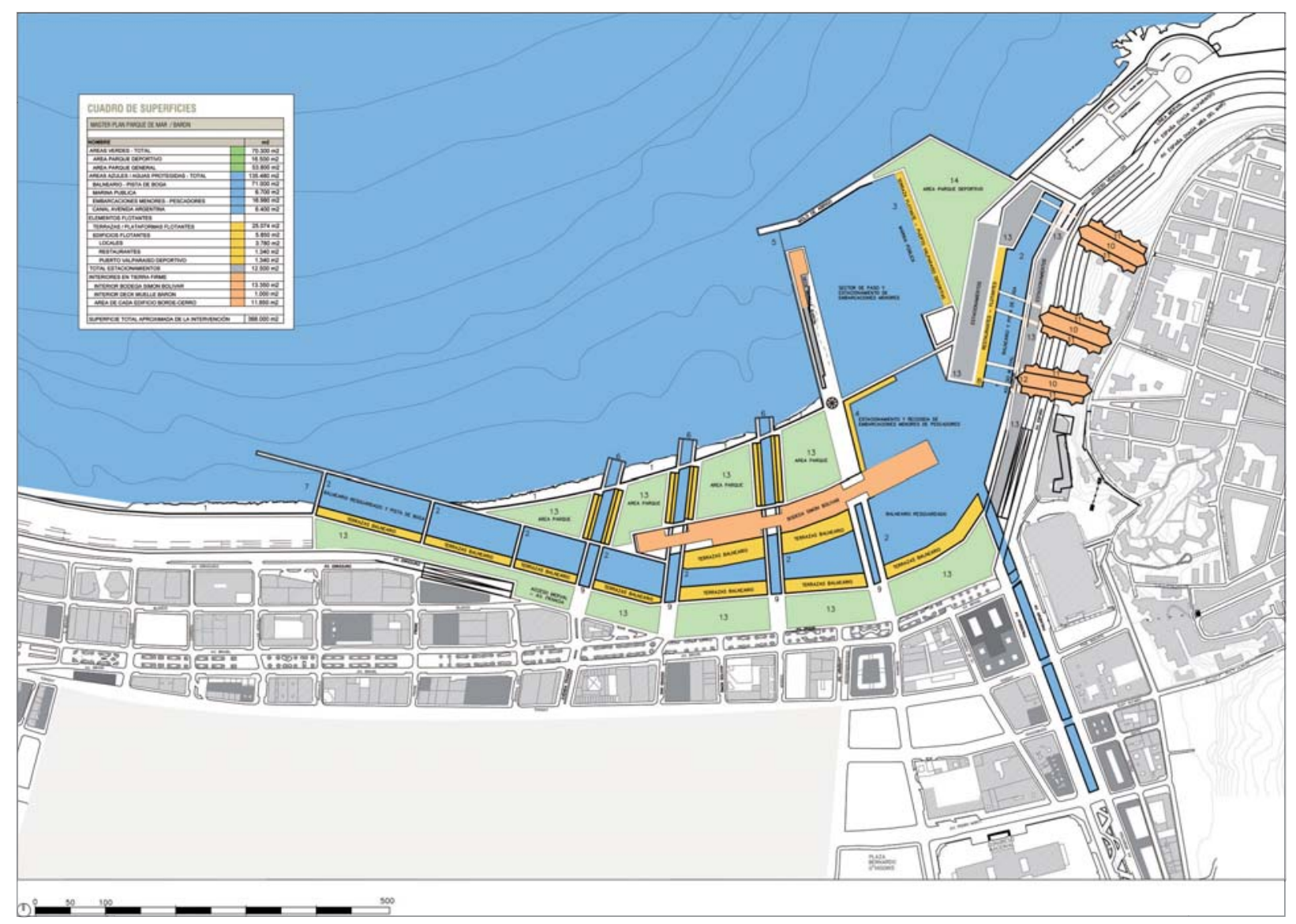

> Figura 10. Plano general del anteproyecto. Fuente: Elaboración propia. 2014

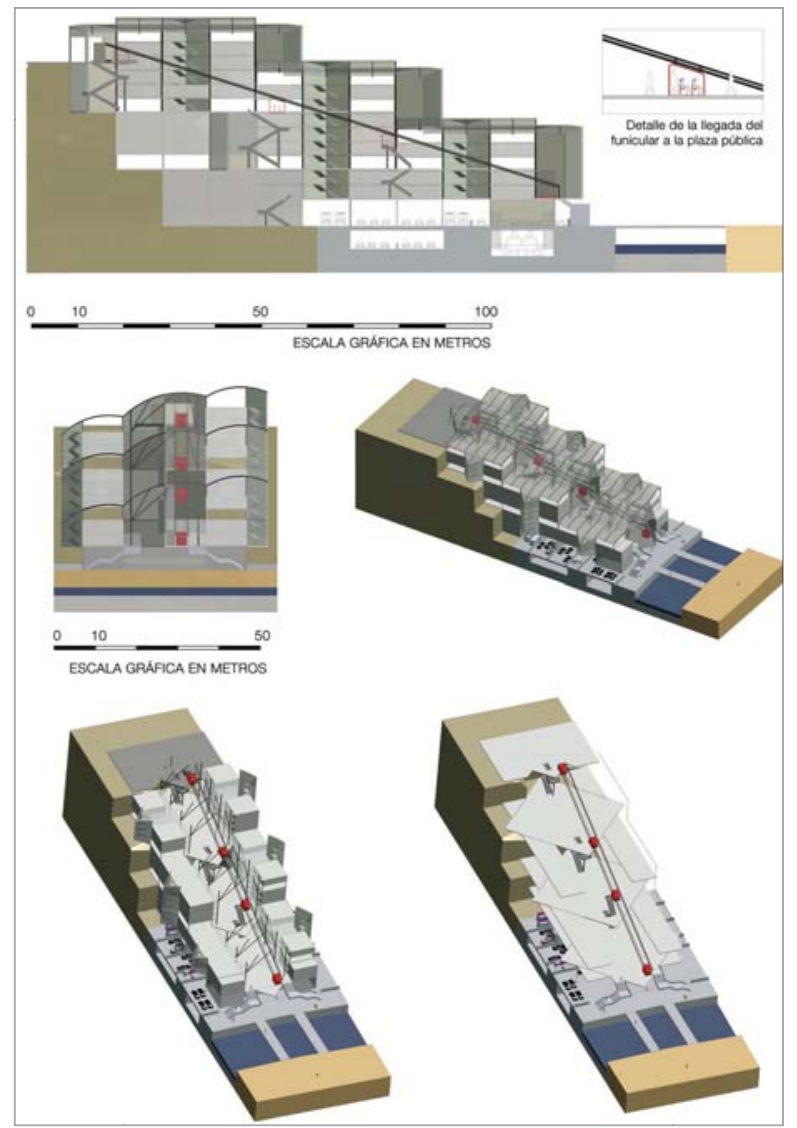

$>$ Figura 11. Planos de los edificios que conectan el cerro Barón con el Parque. Fuente: Elaboración propia, 2014 
calzadas en las azoteas de los edificios y conecta en el parque, abierto a todo público. Los edificios que son privados, crean un patio interior público, donde funciona un colegio y alternativamente un centro de exposiciones y eventos. Este gran ejemplo de arquitectura, hace posible que coexistan lo público y lo privado en perfecta armonía.

Los edificios del Parque de mar Barón, están pensados para esta coexistencia.

\section{De la evacuación del agua de la ciudad}

Los cauces

Al parque marítimo vierten las aguas lluvias a través de los cauces de Avenida Argentina, Avenida Uruguay, Simón Bolívar, San Ignacio, Avenida Francia y Morris, que se originan en los cerros y quebradas de Valparaíso y evitan las inudaciones y anegamientos en el plan. Se recuerda la gran inundación del año 1965, cuando las aguas desbordaron en Barón, sobrepasando en más de un metro el nivel de la calle. En esa ocasion, inundó los subterráneos de la Universidad Católica de Valparaíso.

Actualmente se están realizando obras para mejorar la entrega del agua al mar en el sector de Barón. La licitación contempla el mejoramiento del cauce en todo el largo de la Avenida Argentina.

Realizada una visita al cauce, comprobamos el enorme deterioro de la estructura de la losa (con la enfierradura oxidada a la vista), que consideramos altamente peligrosa. Una serie de machones y obras provisorias de apuntalamiento, representan obstáculos para el normal escurrimiento de las aguas Iluvias en caso de crecidas, limitando drásticamente su capacidad de evacuación. Contribuyen a ello los sedimentos y multiples objetos deshechados. El hecho de estar el cauce bajo tierra (oculto), impide tener conciencia de su potencial peligro.

El anteproyecto considera eliminar la losa del bandejón central de la Avenida Argentina hasta Pedro Montt y rebajar el nivel del suelo del cauce pemitiendo que el mar entre al interior de la ciudad, extendiendo el perímetro del parque.

Con esto se amplía el área de evacuación del agua, se evita el roce de la losa y se transforma en canal abierto. Al estar protejido de las olas podrá fluir sin obstáculos al mar.

Tsunamis

En caso de ocurrencia de tsunami, se cierran las dos compuertas mayores del parque y las cuatro menores. Evitando que el agua entre al parque y la ciudad, disipándose su energía por los rompeolas del borde costero, que serán reforzados.

\section{HIPÓTESIS}

\section{Las partidas del proyecto}

\section{Desde el mar}

Permitir la entrada controlada del mar para generar dársenas, lagunas, canales y playas, dando cabida al programa contemplado. Todas áreas protegidas en caso de tsunamis o temporales, mediante compuertas y rompeolas. Esto mediante excavaciones y consolidación de sus bordes. La tierra extraída permitirá crear un relleno paralelo al muelle, para consolidar la dársena y crear una plataforma de tierra, para dar cabida a las canchas de deportes.

\section{Desde tierra}

Prolongar longitudinalmente las principales avenidas del Almendral hasta el borde costero, atravesando la bodega Simón Bolívar (S.B.) mediante pórticos. El ferrocarril y los automóviles se hunden bajo tierra, junto con nuevos estacionamientos. Incorporando así la Av. Brasil al parque.

3. De la bodega S.B., (inmueble de conservación histórica)

Mantener su estructura, volviendo traslúcido el edificio, mediante una fachada vidriada, para no interferir el horizonte de mar, evitando que sea una espalda entre la ciudad y el parque. Permitir que la entrada de mar genere un canal entre la Avenida Brasil y la bodega S.B., formando una playa interior de aproximadamente 1.000 metros de largo.

\section{Se plantean dos tipos de edificios:}

a. Edificios de mar flotantes, ubicados en los bordes costeros interiores, cuya altura no soprepase la cota del parque y que se eleven con las mareas. Son edificios pensados para restaurantes o comercio; b. Edificios escalonados, ubicados en los acantilados del cerro Barón, en la dirección de sus avenidas, y prolongándose hacia el parque y el borde costero. Edificios conectores del cerro y el parque mediante escaleras, funiculares y rampas.

\section{METODOLOGÍA}

La metodología de prueba de la hipótesis, es fundamentalmente experimental, mediante un modelo hidráulico a escala reducida en una plataforma de ensayos marítimos, en un canal de olas y en un canal de aguas abiertas. Equipamiento que posee el laboratorio del magíster N\&M dependiente de la Escuela de Arquitectura y Diseño de la PUCV. Metodología semejante al que usa el Laboratorio de Hidráulica Nacional, ubicado en Peñaflor y cuyo ex director es el profesor del magíster Señor Alejandro López, quien asesora estos ensayos.

Se quiere ensayar:

1. el control del oleaje, las corrientes marinas y la oxigenación al que estarán expuestas las obras hidráulicas del parque;

2. el funcionamiento de los rompeolas y compuertas de seguridad;

3. el comportamiento de las obras ante un tsunami;

4. la evacuación de los cauces de agua lluvia que van al mar y comprometen la seguridad de la ciudad y del parque, principalmente el de Avenida Argentina.

\section{RESULTADOS}

\section{Desde el mar}

El Parque de mar Puerto Barón es una isla. Es un Parque-isla en el mar.

El borde costero se extiende al interior del parque y genera:

1. una gran playa de $1.000 \mathrm{mts}$.;

2. 1.500 mts. de canales navegables;

3. $6.760 \mathrm{mts}^{2}$. de área para marina pública;

4. $16.900 \mathrm{mts}^{2}$. de área para puerto de embarcaciones menores y de pescadores.

Se tienen varios accesos desde el mar. Estos accesos (compuertas) pueden cerrarse en caso de temporales o tsunamis:

5. compuerta del muelle; $30 \mathrm{mts}$. de ancho;

6. compuertas de los canales; $15 \mathrm{mts}$. de ancho;

7. compuerta poniente. 48 mts. de ancho; 


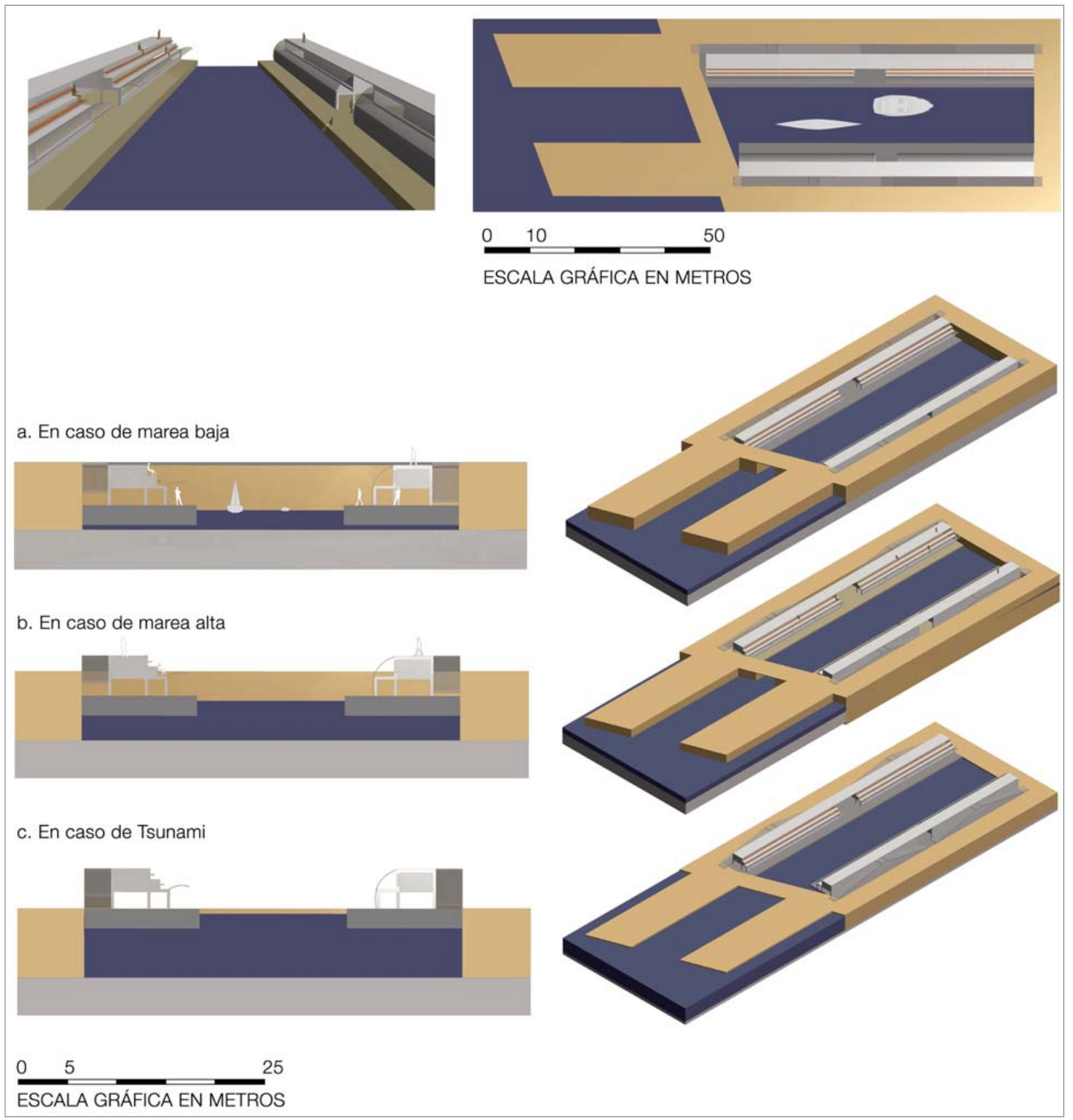

> Figura 12. Planos de los edificios flotantes. Fuente: Elaboración propia, 2014

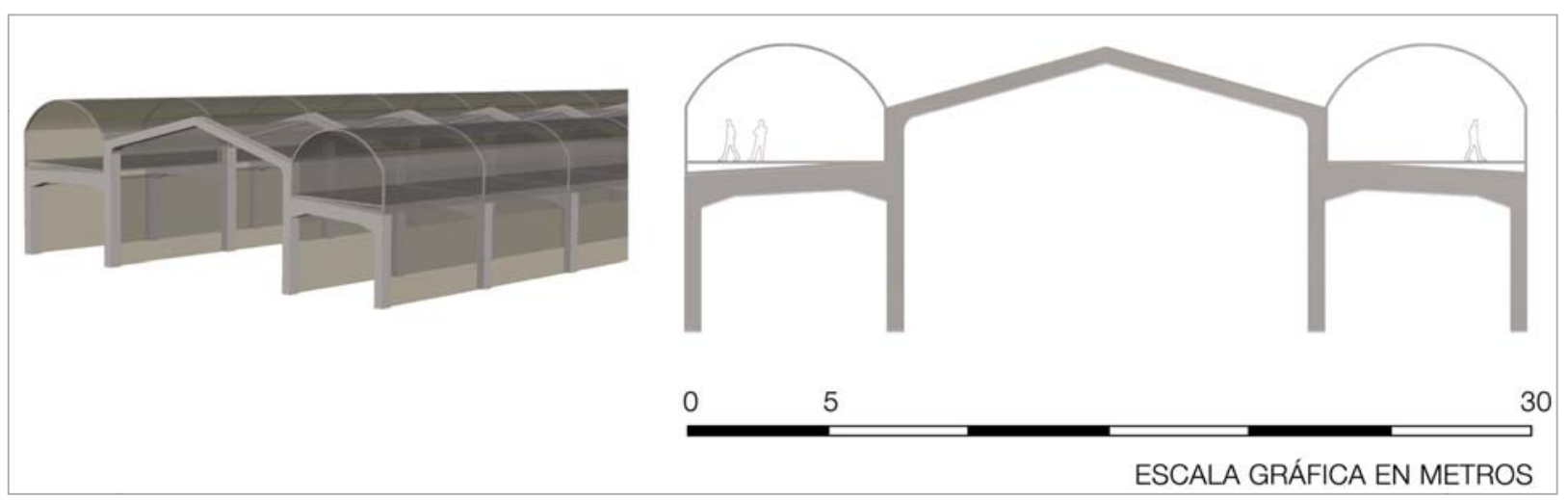

> Figura 13. Planos de remodelación del edificio Simón Bolivar. Fuente: Elaboración propia, 2014 


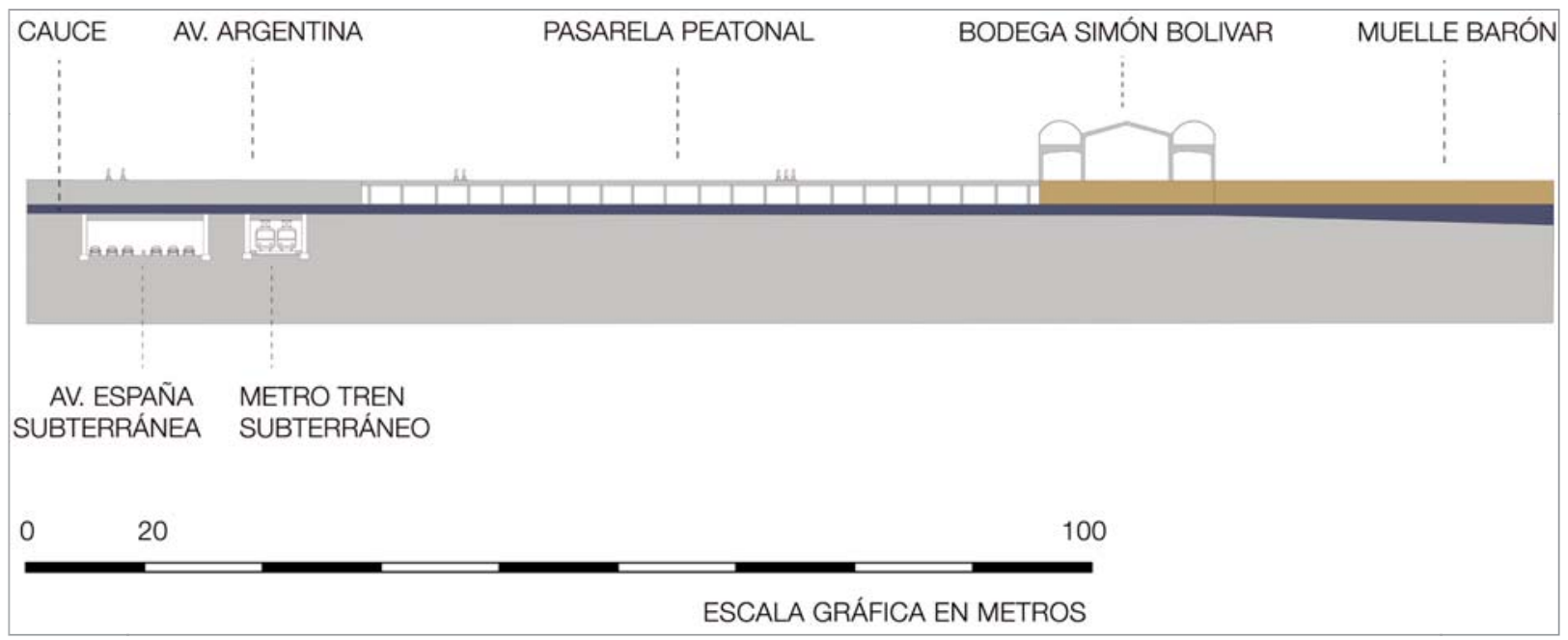

> Figura 14. Corte de la intersección de los cauces con el metro tren y las vías urbanas. Fuente: Elaboración propia, 2014

Se tiene un mar abierto a las olas de $1.040 \mathrm{mts}$. de borde y un mar protegido de olas con $1.700 \mathrm{mts}$. de borde interior.

En los bordes de los canales se ubican unos edificios flotantes de $4 \mathrm{mts}$. de altura y sus terrazas son calzadas conectadas con las calles del Almendral.

8. Son 18 módulos de $30 \times 6 \times 4$ mts. app. con $3.189 \mathrm{mts}^{2}$. de superficie para restaurantes y comercio. Los espacios públicos suman $3.800 \mathrm{mts}^{2}$

\section{Desde tierra}

La ciudad, en el sector del Almendral, se conecta al parque-isla, prolongando la Avenida Francia, San Ignacio, Morris y Rawson hasta el mar.

9. Calzadas, con 1.330 mts. de extensión;

La bodega S. B. deja de ser un muro y no tapa el mar. Es traslúcida atravesada por las calles y avenidas mediante 4 pórticos. El espacio destinado a comercio es de $2.550 \mathrm{mts}^{2}$.

El Cerro Barón se conecta al parque mediante tres edificios escaIonados que siguen el eje de las calles Tocornal, Nelson y Acevedo.

10. Edificios con espacios públicos: plazas interiores, funicular, escaleras mecánicas con $8.300 \mathrm{mts}^{2}$;

11. Edificios con espacios privados: departamentos, oficinas, hotel, con $24.500 \mathrm{mts}^{2}$.

12. Estación para el ferrocarril y paradero de buses con 1.000 $\mathrm{mts}^{2}$;;

13. El parque posee 550 estacionamientos de automóviles con una superficie de $12.500 \mathrm{mts}^{2}$;

14. Área de deportes con $16.500 \mathrm{mts}^{2}$;

15. Áreas verdes con $53.800 \mathrm{mts}^{2}$.

\section{ENSAYOS DEL MODELO EN PLATAFORMA MARITIMA}

\section{Descripción del modelo e hipótesis del programa de ensayos}

Se confeccionó un modelo a escala 1:200 que abarca todo el perímetro del parque, con la batimetría costera hasta la cota 45 de profundidad, con una extensión de 760 mts. mar adentro promedio. Desde esta extensión se ensayarán las olas con un altura máxima de seis metros. (Medición estadísticas de la mayor altura de ola alcanzada en el sector). Se probará con alta marea (1) y baja marea (2) y su incidencia en el borde costero. Se ensayarán los oleajes con las compuertas abiertas (3) y cerradas (4).

Mediante una plataforma superpuesta sobre el nivel del mar, conteniendo agua a una altura de tsunami supuesta de $4 \mathrm{mts}$. (promedio de acuerdo al tsunami del 27 F) y se levantará una compuerta instantáneamente, para provocar la inundación.

Se probará con las compuertas abiertas (5) y cerradas (6).

\section{Resultado de los ensayos}

Estos son resultados preliminares, que miden una primera factibilidad de las hipótesis. Se seguirán realizando ensayos para el ajuste y perfección de las obras planteadas en el anteproyecto.

Estos ensayos arrojan medidas fundamentalmente cualitativas. Con un proyecto de mayor desarrollo, se deben cuantificar las obras que se proponen.

\section{Ensayo del 06.06.2014}

Comportamientos de los ensayos con olas de seis metros y alta marea.

A. Dársena del muelle Barón

1. Sin rompeolas el agua penetra y genera turbulencias en el interior (Ver Figura 15. A1).

2. Con rompeolas se impide que penetre la ola al interior de la dársena, sin necesidad de cerrar la compuerta. En el cabezal del rompeola se produce una pequeña difracción (Ver Figura 15. A2).

B. En los canales Francia, San Ignacio y Rawson, con las compuertas abiertas, se impidió la penetración de la ola mediante tres rompeolas sumergidos, ubicados a 25 metros aguas afuera de la desembocadura de los canales. La forma curva permitió enfrentar y disipar la ola (Ver Figura 15. B).

C. En la compuerta poniente se verificó que al término del rompeola el oleaje penetra, rebota en el muro y se reflejan hacia el interior del canal. Esto hace necesario replantear la hipótesis y remodelar el rompeolas poniente (Ver Figura 15. C).

Para este ensayo no se alcanzó a probar el efecto tsunami. 

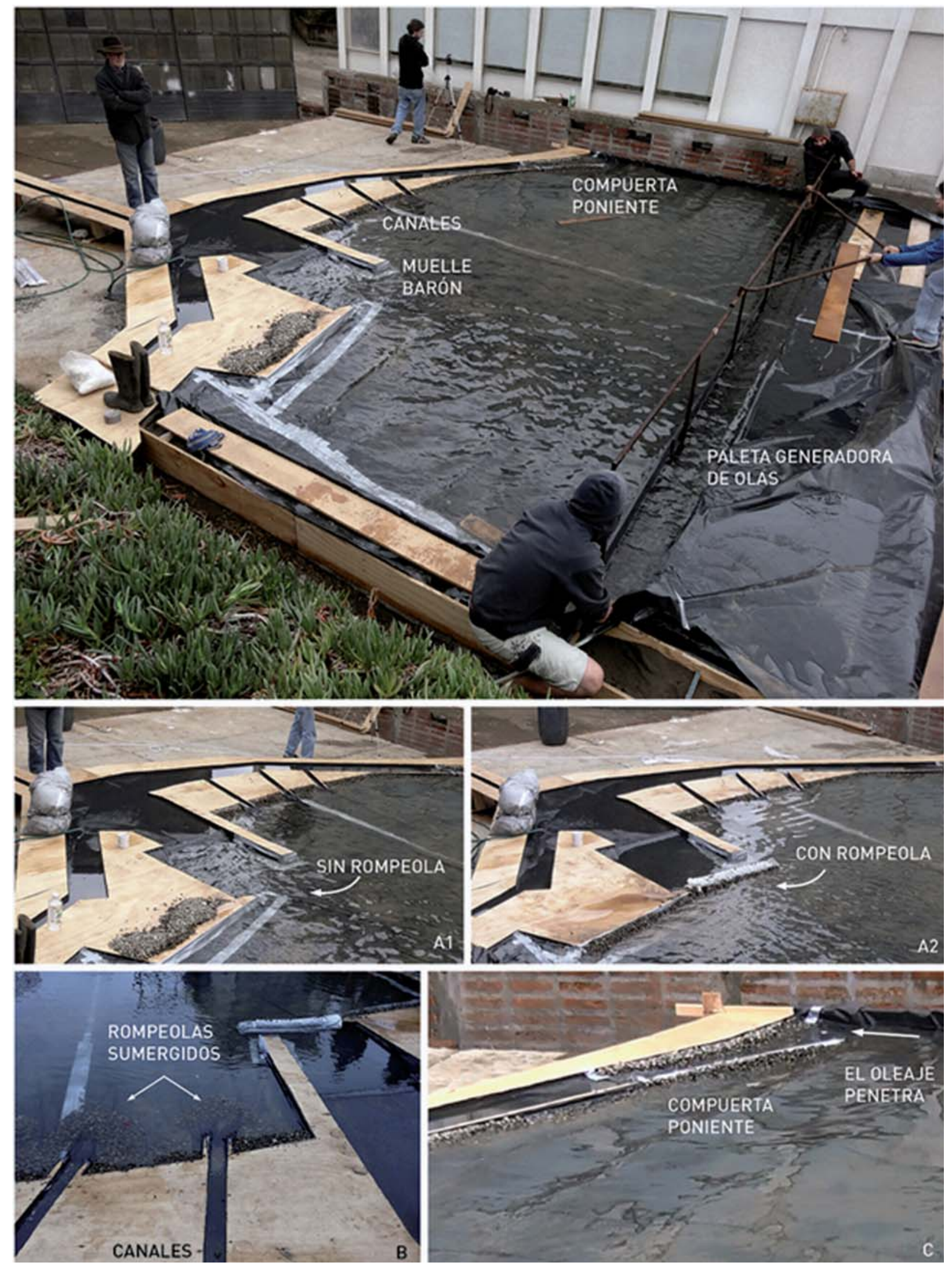

> Figura 15. Resultados de los ensayos de laboratorio de las obras hidráulicas del parque (06.06.2014). Fuente: Elaboración propia, 2014 


\section{CONCLUSIONES}

\section{El destino marítimo}

Si se quisiera proclamar un destino marítimo para Chile, sería necesario que se convierta en un proyecto país, en que estuvieran involucrados todos los estamentos de la nación.

Pero, Chile ¿es consciente que su destino está en el mar? Creemos que no. El poema Amereida plantea que destino es una fidelidad al origen. Valparaíso y las ciudades puertos y costeras no han nacido de una fundación, que les da destinación. Las Leyes de Indias se reservaban el borde costero a la Corona, era la franja del Rey. Ellas mandaban fundar en lo plano, en el valle, en lo favorable. Hoy estamos conscientes de nuestras carencias marítimas: El tráfico marítimo por Chile y por el Pacífico casi no existe. El país no tiene una carretera que una las ciudades del borde costero, ni que nos conecte completamente con la Patagonia y el extremo austral. Alguien dijo hay que "ensanchar y alargar Chile", hay que anexarle las 200 millas del territorio marítimo, hacerlas efectivamente parte de Chile. Un investigador de nuestra Universidad a través de un proyecto Fondef y el apoyo de la Armada, descubrió hidratos de metano en nuestro subsuelo marino, con reservas energéticas para más de 100 años; los resultados descansan en los archivos. Los cultivos marinos le han entregado a Chile enormes divisas, a pesar de la pésima administración de los recursos y el alto grado de contaminación que ha dejado.

Otra prueba palpable de este desapego al mar, lo constituye esta gestión de las autoridades de aprobar un mall en el muelle Barón.

Esta es lamentablemente una "apropiación indebida" de la ciudad, como lo consigna esta convocatoria. Un territorio no puede ser comprendido sólo desde lo material, sino de lo inmaterial que toca a lo social, a lo cultural, como nos lo plantea Alicia Lindón.

[...].Ello evitaría intervenciones inadecuadas, inhospitalarias, brutales, anodinas o sin cualidad y estandarización que, desgraciadamente, se multiplican desenfrenadamente (Paquot, 2009:98-99).

\section{El límite}

Nuestra postura es que las obras del borde costero deben ser el primer y más importante elemento urbano de la ciudad, que este borde coexista con la complejidad de requerimientos ciudadanos, sin entrar en litigio con otras obras y empresas y sin abandonar la arquitectura y el urbanismo que deben cabida a todos los habitantes de Valparaíso.

El Océano Pacífico es un mar abierto, a veces violento, el encuentro entre tierra y mar requiere protecciones que fijan normalmente un límite rígido. En este caso el límite entendido como obstáculo, como negación de un acceso. Este anteproyecto quiere lograr una transparencia de este límite, una abierta invitación, una permeabilidad entre tierra y agua.

Consideramos que el agua es un elemento urbano. Hay que ver el mar no sólo de tierra, sino también desde el agua misma. Hay que romper el límite estricto entre tierra y agua, hay que hacer este límite permeable, como un archipiélago. El agua entra a la tierra, la tierra entra al agua. La tierra remodelada para dar cabida al agua.

Le corresponde a los arquitectos, urbanistas y diseñadores de mar y tierra, mostrar las bondades y maravillas del agua y entregarlas a sus habitantes para su goce y esparcimiento. El agua como baño, como navegación, como pesca, como acuario, como cascadas de oxigenación y sonido, como brillo, luz, reflejos, movimiento, olas.
Hacer presente: [...] y ese mar que tranquilo te baña, te promete futuro esplendor.

\section{BIBLIOGRAFÍA}

AVSOLOMOVICH, I. (2013) "Informe favorable para refacción de Bodega Simón Bolívar". Valparaíso, Artículo en diario Martutino (21.01.2013).

ANDUEZA, P.; ARAVENA, P. (2013) Valparaíso Reclamado, Valparaíso: Perseo.

BALCELLS, I. (1998) Aysén Carta del Mar Nuevo. Santiago: Frío Sur.

BAEZA, D. (2010) Destino marítimo y ciudad, Viña del Mar: TIG. Tesis de Grado, (N\&M).

BAEZA, A.; VIAL, J.; URIBE, J.; IVELIC, B. (1991) "Renovación del estero de Viña del Mar". Revista CA N 63. Santiago: Colegio de Arquitectos.

CRUZ, A. (1954) “Achupallas”, Revista Anales № 1. Valparaíso: UCV.

GUBBINS, V. "Sobre el destino de Valparaíso y el borde costero" en www.gubbinsarquitectos.cl/publicaciones

GARCÍA CANCLINI, N. (2009) Culturas híbridas. Estrategias para entrar y salir de la modernidad. México: Debolsillo.

IVELIC, B.; BAIXAS, J. (1985) “Nuestra Latitud Patagonia”, Revista CA N ${ }^{\circ}$ 40. Santiago: Colegio de Arquitectos.

IOMMI, G. (1984) “El Pacífico es un mar erótico". Viña del Mar: Taller de Investigación Gráfica ead, PUCV.

JOLLY, V. (2011) "El mar como territorio habitable en Valparaíso". Viña del Mar: TIG. Tesis de Grado (N\&M).

LINDÓN, Alicia (2007) "La construcción social de los paisajes invisibles del miedo". In: Nogué, Joan (ed.) La construcción social del paisaje, pp. 219-242. Madrid: Editorial biblioteca nueva S.L.

(2007) "La ciudad y la vida urbana a través de los imaginarios urbanos", EURE Santiago, Vol. 33 № 99, pp. 7-16.

MEYER, H.; BOBBINK, I.; NIJHUIS, S. (2010) Delta Urbanism: The Netherlands. Chicago: APA.

MEYER, H.; MORRIS, D.; WAGGONNER, D. (2012) "New Orleans Netherlands, Common Challenges in Urbanized Deltas”, Magazine Dutch Dialogues, Delft: SUN.

PAQUOT, Thierry (2009) L'espace public. Paris: La Découverte.

PROFESORES EAD, PUCV (1969) “La Avenida del Mar”, Viña del Mar: TIG.

(1970) “Tesis del Pacífico”, Viña del Mar: TIG (Exposición 20 años).

SÁNCHEZ, J. (1971) "Maritorio de los archipiélagos de la Patagonia Occidental", Viña del Mar: TIG.

SAONA, M. (2008) "Concepción del agua como elemento arquitectónico de revitalización”, Viña del Mar: TIG. Tesis de Grado (N\&M).

SOZA, A. (2010) "Puerto en aguas interiores protegida, Aconcagua", Viña del Mar: TIG. Tesis de grado (N\&M).

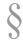

